\title{
Impaired Cerebellar Development and Function in Mice Lacking CAPS2, a Protein Involved in Neurotrophin Release
}

\author{
Tetsushi Sadakata, ${ }^{1}$ Wataru Kakegawa, ${ }^{5}$ Akira Mizoguchi, ${ }^{6}$ Miwa Washida, ${ }^{1}$ Ritsuko Katoh-Semba, ${ }^{7}$ Fumihiro Shutoh, ${ }^{2}$ \\ Takehito Okamoto, ${ }^{2}$ Hisako Nakashima, ${ }^{6}$ Kazushi Kimura, ${ }^{6}$ Mika Tanaka, ${ }^{3}$ Yukiko Sekine, ${ }^{1}$ Shigeyoshi Itohara, ${ }^{4}$ \\ Michisuke Yuzaki, ${ }^{5}$ Soichi Nagao, ${ }^{2}$ and Teiichi Furuichi ${ }^{1}$ \\ ${ }^{1}$ Laboratory for Molecular Neurogenesis, ${ }^{2}$ Laboratory for Motor Learning Control, ${ }^{3}$ Research Resource Center, and ${ }^{4}$ Laboratory for Behavioral Genetics, \\ RIKEN Brain Science Institute, Wako, Saitama 351-0198, Japan, 5 Department of Physiology, School of Medicine, Keio University, Tokyo 160-8582, Japan, \\ ${ }^{6}$ Department of Anatomy, School of Medicine, Mie University, Tsu, Mie 514-8507, Japan, and 'Department of Perinatology, Institute for Developmental \\ Research, Aichi Human Service Center, Kasugai, Aichi 480-0392, Japan
}

$\mathrm{Ca}^{2+}$-dependent activator protein for secretion 2 (CAPS2/CADPS2) is a secretory granule-associated protein that is abundant at the parallel fiber terminals of granule cells in the mouse cerebellum and is involved in the release of neurotrophin-3 (NT-3) and brain-derived neurotrophic factor (BDNF), both of which are required for cerebellar development. The human homolog gene on chromosome 7 is located within susceptibility locus 1 of autism, a disease characterized by several cerebellar morphological abnormalities. Here we report that CAPS2 knock-out mice are deficient in the release of NT-3 and BDNF, and they consequently exhibit suppressed phosphorylation of Trk receptors in the cerebellum; these mice exhibit pronounced impairments in cerebellar development and functions, including neuronal survival, differentiation and migration of postmitotic granule cells, dendritogenesis of Purkinje cells, lobulation between lobules VI and VII, structure and vesicular distribution of parallel fiber-Purkinje cell synapses, paired-pulse facilitation at parallel fiber-Purkinje cell synapses, rotarod motor coordination, and eye movement plasticity in optokinetic training. Increased granule cell death of the external granular layer was noted in lobules VI-VII and IX, in which high BDNF and NT-3 levels are specifically localized during cerebellar development. Therefore, the deficiency of CAPS2 indicates that CAPS2-mediated neurotrophin release is indispensable for normal cerebellar development and functions, including neuronal differentiation and survival, morphogenesis, synaptic function, and motor leaning/control. The possible involvement of the CAPS2 gene in the cerebellar deficits of autistic patients is discussed.

Key words: CAPS2/CADPS2; CAPS1/CADPS1; neurotrophin; BDNF; NT-3; cerebellum

\section{Introduction}

$\mathrm{Ca}^{2+}$-dependent activator protein for secretion 2 (CAPS2/ CADPS2) (Cisternas et al., 2003; Speidel et al., 2003; Sadakata et al., 2004, 2007a) is a paralog of CAPS1/CADPS1 that is essential for $\mathrm{Ca}^{2+}$-triggered dense-core vesicle (DCV) exocytosis (Berwin et al., 1998; Tandon et al., 1998; Renden et al., 2001). CAPS participates in an ATP-dependent priming step as a phosphatidyl inositol 4,5-bisphosphate-binding and DCV-binding protein in response to increases in intracellular $\mathrm{Ca}^{2+}$ (Grishanin et al., 2004), and it is also known to interact with the dopamine receptor (Binda et al., 2005). Study of CAPS1-deficient mice has suggested that CAPS1 is involved in the catecholamine loading of DCVs in embryonic chromaffin cells (Speidel et al., 2005). CAPS2 is abundantly localized in the parallel fiber (PF) terminals of cerebellar granule cells and associates with vesicles containing

Received May 30, 2006; revised Jan. 23, 2007; accepted Jan. 27, 2007.

This study was supported by grants-in-aid for Scientific Research from the Japanese Ministry of Education, Culture, Sports, Science, and Technology (Grant 17700322), the Japan Society for the Promotion of Science, and the RIKEN Institute of Physical and Chemical Research.

Correspondence should be addressed to Teiichi Furuichi, Laboratory for Molecular Neurogenesis, RIKEN Brain Science Institute, 2-1 Hirosawa, Wako, Saitama 351-0198, Japan. E-mail: tfuruichi@brain.riken.go.jp.

DOI:10.1523/JNEUROSCI.2279-06.2007

Copyright $\odot 2007$ Society for Neuroscience $\quad$ 0270-6474/07/272472-11\$15.00/0 two neurotrophins, brain-derived neurotrophic factor (BDNF) and neurotrophin-3 (NT-3), and a DCV marker, chromogranin B (Sadakata et al., 2004, 2006). In cerebellar primary cultures, the overexpression of exogenous CAPS2 augments the release of these neurotrophins, thus promoting cell survival (Sadakata et al., 2004).

Neurotrophins play an indispensable role in neuronal differentiation and survival (Bibel and Barde, 2000; Huang and Reichardt, 2001; Lessmann et al., 2003; Segal, 2003), as well as in synaptic plasticity (Thoenen, 1995; Schinder and Poo, 2000; Lu, 2003; Kovalchuk et al., 2004). Many reports have described the importance of BDNF and NT-3 in the postnatal development of the cerebellum (Lindholm et al., 1997; Schwartz et al., 1997; Bates et al., 1999; Carter et al., 2002). In the mouse cerebellum, BDNF and NT-3 released by granule cells bind to their Trk receptors, TrkB and TrkC, respectively, on both postsynaptic Purkinje cells (PCs) and presynaptic granule cells, thereby leading to Trk signaling in an autocrine-paracrine and anterograde manner (Lindholm et al., 1997). Mice genetically lacking either BDNF (Jones et al., 1994; Schwartz et al., 1997; Carter et al., 2002) or NT-3 (Bates et al., 1999) also showed the pivotal role of these two neurotrophins in cerebellar development.

The human CAPS2/CADPS2 gene is located on chromosome 
7q31.32 (Cisternas et al., 2003) within autism susceptibility locus 1 (AUTS1) (International Molecular Genetic Study of Autism Consortium, 2001). Autistic spectrum disorders are a severe neurodevelopmental disorders marked by profound disturbances in social, communicative, and behavioral functioning (World Health Organization, 1992; American Psychiatric Association, 1994) with a prevalence of 3-6/1000 and a male-to-female ratio of 3:1 (Muhle et al., 2004). A recent study by our group showed autistic-like cellular and behavioral phenotypes in CAPS2 knockout mice and aberrant CAPS2 mRNA splicing in autistic patients (Sadakata et al., 2007b). It has been demonstrated that autistic patients exhibit several abnormalities in cerebellar morphology and function, including hypoplasia of the cerebellar lobules (Courchesne et al., 1988; Pierce and Courchesne, 2001) and impaired eye movement (Takarae et al., 2004) and motor coordination (Manjiviona and Prior, 1995). In this study, to elucidate whether or not the loss of CAPS2 function in mice would lead to abnormal cerebellum-related phenotypes, we investigated the structure, development, and function of the CAPS2 knock-out mouse cerebellum. Our results demonstrated the indispensable role of CAPS2-mediated neurotrophin release in normal cerebellar development and function. In addition, to broaden our understanding of the role of CAPS2 in the cerebellum, we discussed these results in relation to the cerebellar abnormalities reported in autistic patients.

\section{Materials and Methods}

CAPS2 knock-out mice. Recently generated CAPS2 knock-out mice (Sadakata et al., 2007b) were used in the present study. Briefly, a $12 \mathrm{~kb}$ genomic fragment containing exon 1 of mouse CAPS2 from C57BL/6 mice was used to construct the targeting vectors. For positive selection, the SmaI-SmaI fragment containing the full length of exon 1 was replaced by the Pgk-neo gene cassette flanked by the loxP sites. For negative selection, the diphtheria toxin A fragment gene cassette was added to the $5^{\prime}$ end of the targeting vector. After transfection of MS12 embryonic stem (ES) cells [C57BL/6 mouse embryonic stem cell line (Kawase et al., 1994)] by electroporation, targeted clones were screened for G418 resistance and analyzed by Southern blot analysis. Chimeric mice were generated by injection of the targeted MS12 ES cells into BALB/c blastocysts and mated with wild-type C57BL/6J mice to obtain heterozygous mutant mice. All of the engineered animals studied were backcrossed onto C57BL/6J for more than five generations.

Antibodies. Guinea pig polyclonal anti-CAPS2 antibody and rabbit polyclonal anti-CAPS1 antibody (Sadakata et al., 2004) were used for the immunohistochemical analysis (used at dilution of 1:10,000 and 1:5000, respectively). Rabbit anti-NT-3 (Katoh-Semba et al., 1996), anti-BDNF (Katoh-Semba et al., 1997), and anti-phosphorylated Trk antibodies (pTrk) (Tyr490; catalog \#9141; Cell Signaling Technology, Beverly, MA) were used for the immunohistochemical analysis (used at dilution of $1: 150,1: 100$, and $1: 10$, respectively). Mouse monoclonal anti-calbindin D-28K (C9848; Sigma, St. Louis, MO), anti-microtubule-associated protein MAP2 $(2 a+2 b)$ (M1406; Sigma), and anti-vesicular glutamate transporter (VGLUT2) (MAB5504; Millipore, Temecula, CA) antibodies were used for immunohistochemistry and immunocytochemistry (used at dilution of 1:500,1:1000, 1:5000, and 1:4000, respectively). Alexa-conjugated anti-guinea pig, rabbit, and mouse antibodies (Invitrogen, Carlsbad, CA) were used as secondary antibodies at a 1000-fold dilution.

Immunohistochemistry. For BDNF and NT-3 immunohistochemistry, postnatal day 8 (P8) C57BL/6J mice were anesthetized with diethyl ether and transcardially perfused with PBS and then with Zamboni's fixative [2\% paraformaldehyde (PFA) in $0.1 \mathrm{~m}$ phosphate buffer (PB), $\mathrm{pH} 7.4$, containing $0.2 \%$ picric acid]. The brains were dissected out, postfixed in Zamboni's fixative at $4^{\circ} \mathrm{C}$ for $5 \mathrm{~h}$, and cryoprotected by immersion in $15 \%$ sucrose in PBS overnight at $4^{\circ} \mathrm{C}$. After embedding in Tissue-Tek OCT compound (Sakura Finetechnical, Tokyo, Japan), the brains were frozen and sectioned sagittally or coronally at a thickness of $14 \mu \mathrm{m}$ with a cryostat (CM1850; Leica, Frankfurt, Germany) at $-18^{\circ} \mathrm{C}$. The sections were air dried for $1 \mathrm{~h}$ and rinsed in PBS three times. After blocking with $5 \%$ bovine serum albumin (BSA) in PBS at room temperature for $1 \mathrm{~h}$, the sections were reacted at $4^{\circ} \mathrm{C}$ overnight with the primary antibody in an immunoreaction buffer $(2 \times$ PBS containing $0.3 \%$ Triton X-100 and $1 \%$ $\mathrm{BSA}$ ), rinsed in PBS, and then reacted at room temperature for $1 \mathrm{~h}$ with the secondary antibody in the immunoreaction buffer and rinsed in PBS. The immunoreacted sections were mounted with Vectashield (Vector Laboratories, Peterborough, UK) mounting medium. Immunohistochemical staining with the other antibodies was performed as reported previously (Sadakata et al., 2004, 2006).

Terminal deoxynucleotidyl transferase-mediated biotinylated UTP nick end labeling assay. Apoptotic cells were counted with an In Situ Cell Death Detection kit, TMR red (Roche Molecular Systems, Alameda, CA), according to the instructions of the manufacturer, and $14-\mu \mathrm{m}$-thick cerebellar sections of P8 CAPS2 ${ }^{-1-}(n=4)$ and wild-type littermates $(n=$ 4) were used for the assay.

Golgi staining. Golgi staining was performed by using an FD Rapid GolgiStain kit (FD NeuroTechnologies, Ellicott City, MD) according to the instructions of the manufacturer. The sections were frozen with liquid nitrogen, and $60-\mu \mathrm{m}$-thick sections of wild-type and CAPS $2^{-/-}$cerebella (P8 and P28) were cut in a cryostat.

Electron microscopy. For electron microscopy of paraformaldehydefixed sections, wild-type and CAPS2 ${ }^{-/-}$mice (P15 and P84) were deeply anesthetized with ether and perfused for $15 \mathrm{~min}$ with freshly prepared $2 \%$ glutaraldehyde and 2\% PFA in $0.1 \mathrm{M} \mathrm{PB}$. Brains were removed by dissection, soaked in the same fixative at $4^{\circ} \mathrm{C}$ for $4 \mathrm{~h}$, and cut with a vibratome into several sections ( $\sim 400 \mu \mathrm{m}$ thick). Tissue blocks were then postfixed in $1 \%$ osmium tetroxide in $0.1 \mathrm{~m} \mathrm{~PB}$, dehydrated through a graded series of ethanol solutions, and embedded in epoxy resin. Ultrathin sections of lobules IV, V, VI and VII were cut from both surfaces of vibratome sections. The ultrathin sections were stained with uranyl acetate and lead citrate before examination with an electron microscope (JEM 1013 EX; Jeol, Tokyo, Japan). Cerebellar samples from three mice of each genotype were used. A 100,000 $\mu \mathrm{m}^{2}$ area from each animal was analyzed.

Cerebellar primary cultures. Cerebellar primary cultures were prepared basically as described in a previous study (Sadakata et al., 2004). In brief, after rapid decapitation the P0 cerebella of wild-type or CAPS2 ${ }^{-1-}$ mice were dissected out, digested for $13 \mathrm{~min}$ at $37^{\circ} \mathrm{C}$ with $0.1 \%$ trypsin (Sigma) and $0.05 \%$ DNase I (Boehringer Mannheim, Indianapolis, IN) in $\mathrm{Ca}^{2+}$ / $\mathrm{Mg}^{2+}$-free HBSS [HBSS-CaMg(-)] (Sigma), and washed with HBSS$\mathrm{CaMg}(-)$. They were then triturated by repeated passage through a $1 \mathrm{ml}$ plastic micropipette tip in HBSS-CaMg $(-)$ containing 0.05\% DNase I and $12 \mathrm{mM} \mathrm{MgSO}_{4}$ and washed with a serum-free Eagle minimal essential medium-based chemical-conditioned medium supplemented with $0.25 \%(\mathrm{w} / \mathrm{v})$ glucose (Nacalai Tesque, Kyoto, Japan), $10 \mu \mathrm{g} / \mathrm{ml}$ insulin (Sigma), $0.1 \mathrm{~nm}$ L-thyroxine (Sigma), $0.1 \mathrm{mg} / \mathrm{ml}$ apotransferrin (Sigma), $1 \mathrm{mg} / \mathrm{ml} \mathrm{BSA} \mathrm{(Sigma),} 2 \mathrm{~mm}$ L-glutamine (Nacalai Tesque), $1 \mu \mathrm{g} / \mathrm{ml}$ aprotinin (Sigma), $30 \mathrm{~nm}$ sodium selenite (Merck, Darmstadt, Germany), $100 \mathrm{U} / \mathrm{ml}$ penicillin (Banyu Pharmaceutical, Tokyo, Japan), and $135 \mu \mathrm{g} / \mathrm{ml}$ streptomycin (Meiji Seika, Tokyo, Japan). The dissociated cells were plated at $5 \times 10^{5}$ cells per glass coverslip ( $12 \mathrm{~mm}$ in diameter; Matsunami, Tokyo, Japan) coated with poly-L-lysine (Sigma) and then cultured in the medium at $37^{\circ} \mathrm{C}$ under a humidified $5 \% \mathrm{CO}_{2}$ atmosphere.

Electrophysiology. Parasagittal cerebellar slices (250 $\mu \mathrm{m}$ thick) were prepared from CAPS2 ${ }^{-/-}$mice and wild-type littermates (P15-P21 and P43-P54) in accordance with the guidelines of our institution. Wholecell voltage-clamp recordings were made from visually identified PCs with an Axopatch 200B amplifier (Molecular Devices, Palo Alto, CA), and the pClamp system (version 9.2; Molecular Devices) was used for data acquisition and analysis. Patch pipettes were pulled from borosilicate glass capillaries to achieve a resistance of 3-5 $\mathrm{M} \Omega$ when filled with a solution containing the following (in $\mathrm{mM}$ ): $65 \mathrm{~K}$-gluconate, $65 \mathrm{Cs}$ methanesulfonate, $10 \mathrm{KCl}, 1 \mathrm{MgCl}_{2}, 4 \mathrm{Na}_{2} \mathrm{ATP}, 1 \mathrm{Na}_{2} \mathrm{GTP}, 20$ HEPES, 5 sucrose, and 0.4 EGTA, pH 7.3 (295 mOsm/ $/ \mathrm{kg})$. The external Ringer's solution contained $125 \mathrm{~mm} \mathrm{NaCl}, 2.5 \mathrm{~mm} \mathrm{KCl}, 2 \mathrm{mM} \mathrm{CaCl}_{2}, 1 \mathrm{mM} \mathrm{MgCl}_{2}$, $26 \mathrm{~mm} \mathrm{NaHCO} 3,1.25 \mathrm{~mm} \mathrm{NaH}_{2} \mathrm{PO}_{4}, 10 \mathrm{~mm}$ D-glucose, and $0.1 \mathrm{~mm}$ picrotoxin (to inhibit GABAergic synapses) and was bubbled with $95 \%$ 
$\mathrm{O}_{2}$ and $5 \% \mathrm{CO}_{2}$ at room temperature $\left(24^{\circ} \mathrm{C}\right)$. To evoke PF-EPSCs, a stimulating electrode was placed in the molecular layer (ML) (pulse width, $20-100 \mu \mathrm{s} ; \sim 220 \mu \mathrm{A}$ ), and selective stimulation of PFs was confirmed by the paired-pulse facilitation (PPF) of PF-EPSCs with a $50 \mathrm{~ms}$ stimulation interval. The current traces were filtered at $1 \mathrm{kHz}$ and digitized at $4 \mathrm{kHz}$.

Animals used for behavioral analyses. All experimental protocols were approved by the RIKEN Institutional Animal Care and Use Committee. The mice were housed on a $12 \mathrm{~h} \mathrm{light/dark} \mathrm{cycle,} \mathrm{with} \mathrm{the} \mathrm{dark} \mathrm{cycle}$ occurring from 8:00 P.M. to 8:00 A.M. All mice used were littermates from mated heterozygotes. The experimenters were blind to the genotype in all behavioral tests.

Rotarod testing. Rotarod testing was performed as described previously (Lynch et al., 1975) using the Rota-Rod Treadmill for Mice 7600 (Ugo Basile, Comerio, Italy). Briefly, the male mouse was required to run backwards to maintain its position on top of a rod revolving at $24 \mathrm{rpm}$. Each time it fell, the mouse was put back on the rod until it had run for a total of $3 \mathrm{~min}$ on the rod. Time was not counted while the mouse was off the rod. The total number of falls was recorded.

Eye movement analysis. Six-month-old CAPS2 ${ }^{-/-}$mice and wild-type littermates were used for the eye movement analysis, as described previously (Katoh et al., 1998). Under pentobarbital anesthesia $(60 \mathrm{mg} / \mathrm{kg}$ body weight; Nacalai Tesque) and aseptic conditions, a platform for head fixation was created on the mouse cranium with four small screws and one long bolt of synthetic resin. Two days after surgery, the mouse was mounted on a turntable surrounded by a checkerboard pattern (check size, $\left.4^{\circ}\right)$ cylindrical screen $(64 \times 70 \mathrm{~cm}$, diameter $\times$ height $)$, with its head fixed and the body loosely restrained in a plastic cylinder. Two types of reflex eye movement were measured: the horizontal vestibulo-ocular reflex (HVOR) and the horizontal optokinetic response (HOKR). The HVOR was tested with sinusoidal oscillations of the turntable (frequency, $0.11-0.5 \mathrm{~Hz}$; peak-to-peak amplitude, $10^{\circ}$ ) in the horizontal plane in the dark; the HOKR was tested with sinusoidal oscillations of the screen by $10-20^{\circ}$ (peak-to-peak) at $0.11-0.33 \mathrm{~Hz}$ in the light (maximum screen velocity, $3.5-10.5^{\circ} / \mathrm{s}$ ). More than 10 cycles of evoked eye movements free from artifacts attributable to blinks and saccades were averaged, and the mean amplitude and phase were calculated by a modified Fourier analysis (Jastreboff, 1979). The gain of the eye movements was defined as the ratio of the peak-to-peak amplitude of the eye movements to that of the turntable or screen oscillations. The phase was defined as $0^{\circ}$ when the peak of the eye movement was opposite to the peak of the turntable oscillations in the HVOR and when the peak of the eye movement matched the screen oscillations in the HOKR. The adaptability of the HOKR was examined by exposing the mouse to $1 \mathrm{~h}$ of sustained screen oscillations by $15^{\circ}$ at $0.17 \mathrm{~Hz}$ (maximum screen velocity, $7.9^{\circ} / \mathrm{s}$ ) in the light.

Statistical analysis. Statistical analysis was performed with Statcel software (OMS, Saitama, Japan). Comparisons of the data were assessed with Student's $t$ test or the Mann-Whitney $U$ test according with unequal or equal variance. A $p$ value of $<0.05$ was considered statistically significant.

\section{Results}

\section{Expression of CAPS family proteins in the CAPS2 $2^{-/-}$ mouse cerebellum}

We used an immunohistochemical approach to examine CAPS family protein expression in the cerebella of a recently generated strain of CAPS2 knock-out mice (Sadakata et al., 2007b). In the cerebella of wild-type $\left(\right.$ CAPS $\left.2^{+/+}\right)$mice, CAPS2 immunoreactivity was predominantly localized in the ML (at PF terminals synapsing on Purkinje cell spines) and, less densely, in the internal granular layer (IGL) (Fig. $1 A$ ) as reported previously (Sadakata et al., 2004, 2006). In contrast, CAPS1 immunoreactivity was localized in a punctate pattern on the primary dendrites and soma of Purkinje cells and was also observed near the glomeruli of the IGL (at P8 in Fig. 1C) (P28 in supplemental Fig. 1, available at www. jneurosci.org as supplemental material). Because the localization of CAPS1 overlapped with that of VGLUT2, a marker for climb-
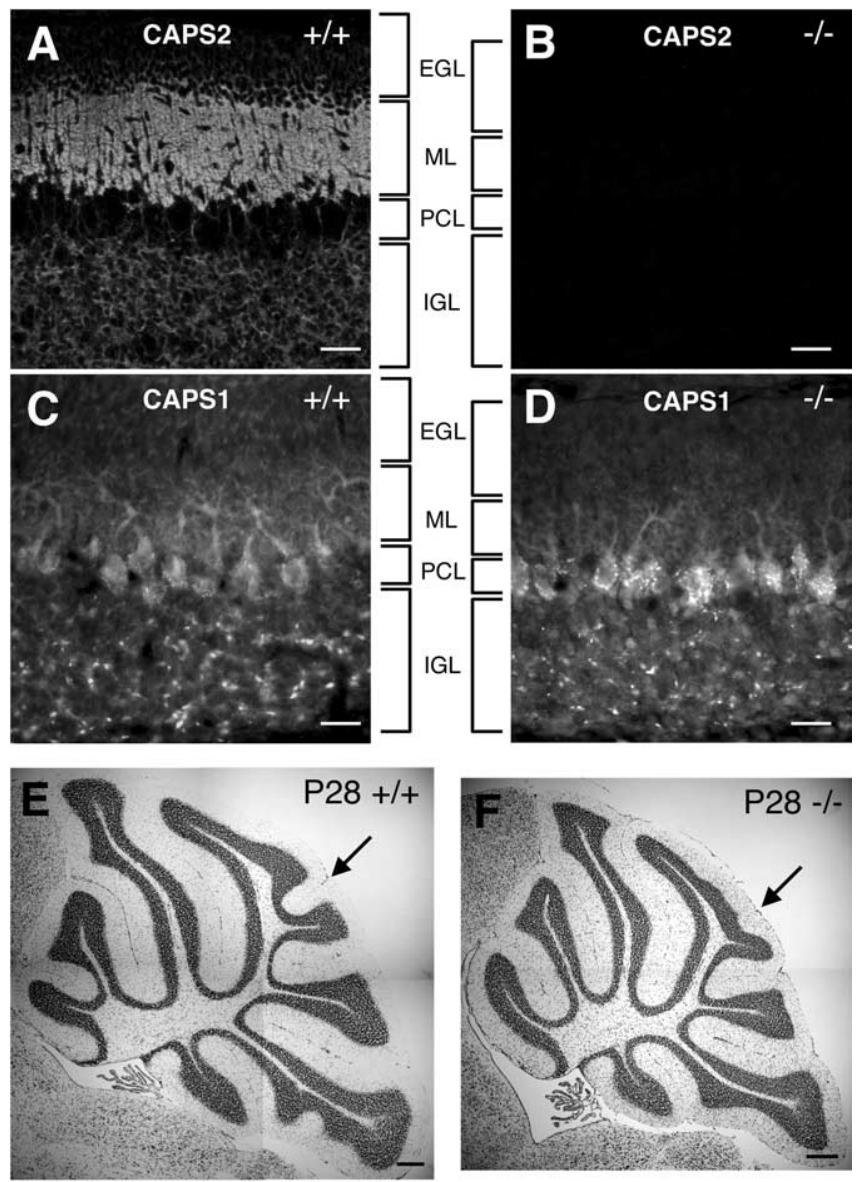

Figure 1. Distribution of CAPS family proteins and aberrant lobulation in the CAPS2 mouse cerebellum. $\boldsymbol{A}, \boldsymbol{B}$, To generate CAPS2 knock-out mice, the Smal-Smal fragment containing full-length CAPS2 exon 1 was replaced by the Pgk-neo gene cassette (see Materials and Methods). Sagittal sections of P8 wild-type $(\boldsymbol{A})$ and $C A P S 2^{-1-}(\boldsymbol{B})$ cerebella were immunolabeled with an anti-CAPS2 antibody. Confocal fluorescence images were taken from the cerebellar cortex. $\boldsymbol{C}, \boldsymbol{D}$, Sagittal sections of P8 wild-type $(\boldsymbol{C})$ and $C A P S 2^{-1-}(\boldsymbol{D})$ cerebella were immunolabeled with an anti-CAPS1 antibody. PCL, Purkinje cell layer. Scale bars, 20 $\mu \mathrm{m} . \boldsymbol{E}, \boldsymbol{F}$, Sagittal sections of $\mathrm{P} 28$ wild-type $(\boldsymbol{E})$ and $C A P S 2^{-/-}(\boldsymbol{F})$ cerebella were stained with cresyl violet. Arrows point to the intercrural fissure that normally separates lobules $V I$ and VII. Scale bars, $250 \mu \mathrm{m}$.

ing fiber (CF) terminals (supplemental Fig. 1, available at www. jneurosci.org as supplemental material), and because CAPS1 was shown previously to be expressed in the inferior olive (Sadakata et al., 2006), CAPS1 is most likely localized in the CF terminals that synapse on the proximal dendrites of Purkinje cells, in contrast to CAPS2 localization in the PF terminals. In the cerebella of homozygote $\left(C A P S 2^{-/-}\right.$) mice, CAPS2 protein could not be detected (Fig. $1 B$ ), but CAPS1 protein was observed on the primary dendrites and soma of Purkinje cells (Fig. 1D) as seen in the cerebella of CAPS2 ${ }^{+/+}$littermates (Fig. 1C). These observations indicate that CAPS2 knock-out mice have completely lost the ability to produce CAPS2 protein with no significant alteration in CAPS1 protein expression.

\section{Aberrant cytoarchitecture in the CAPS2 knock-out cerebellum}

CAPS2 $2^{-/-}$mice did not exhibit any overt abnormalities of the gross brain anatomy, with the exception of the absence of the intercrural fissure between lobules VI and VII, which was an obvious deficit in the CAPS2 $2^{-/-}$cerebellum during histological 


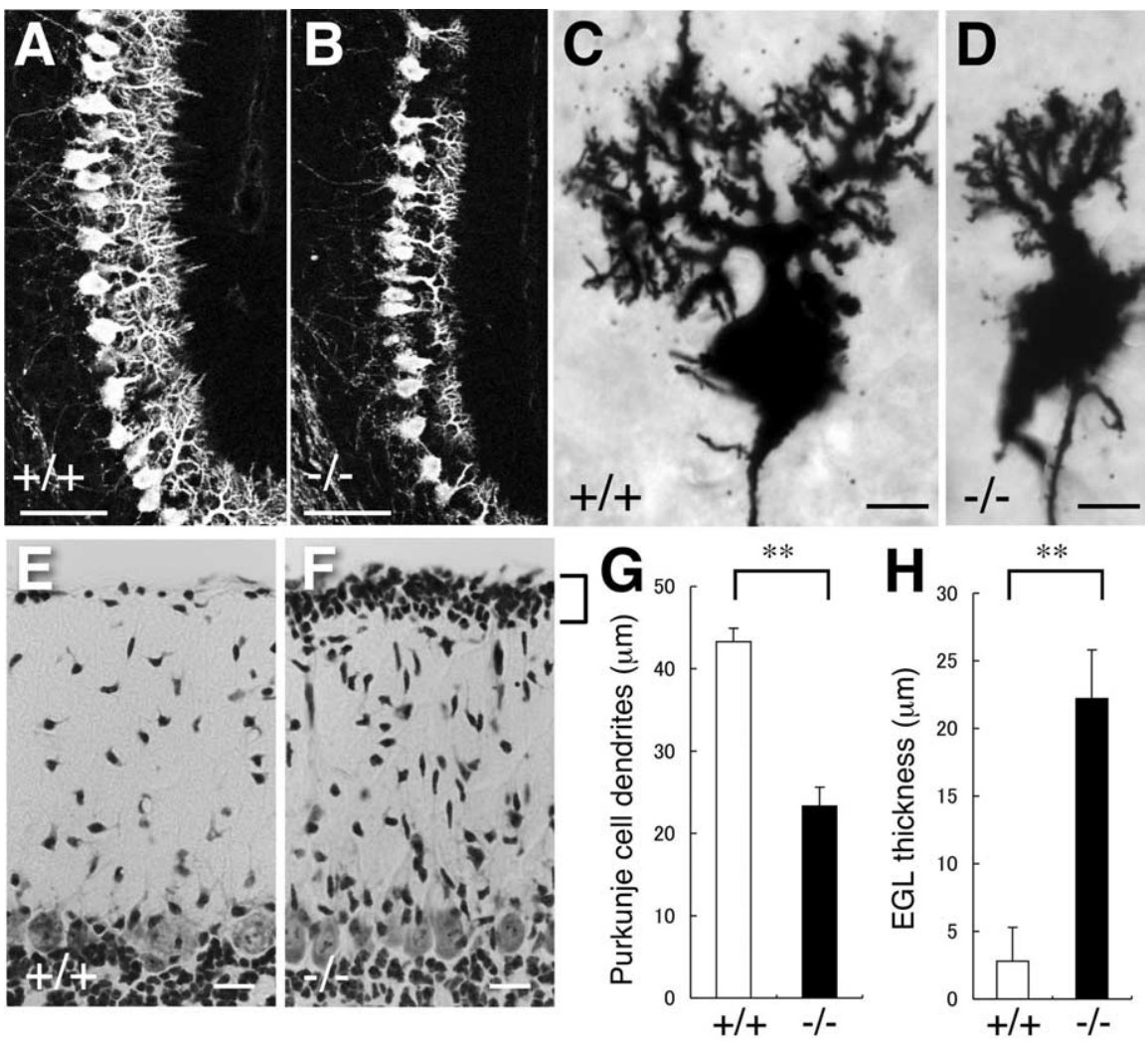

Figure 2. Impaired dendritic arborization of Purkinje cells and delayed granule cell migration in CAPS2 ${ }^{-/-}$mouse cerebellum. $\boldsymbol{A}, \boldsymbol{B}$, Sagittal sections of P8 wild-type $(\boldsymbol{A})$ and $C A P S 2^{-1-}(\boldsymbol{B})$ cerebella were immunolabeled with an anti-calbindin antibody. Fluorescence images near the bottom of the primary fissure. Scale bars, $50 \mu \mathrm{m}$. $\boldsymbol{C}, \boldsymbol{D}$, Dendritic arbors of P8 wild-type $(\boldsymbol{C})$ and CAPS2 $^{-/-}(\boldsymbol{D})$ Purkinje cells in lobule V were visualized by Golgi staining. Scale bars, $10 \mu \mathrm{m}$. $\boldsymbol{E}, \boldsymbol{F}$, Sagittal sections of P17 wild-type $(\boldsymbol{E})$ and CAPS2 $^{-/-}(\boldsymbol{F})$ cerebella were stained with cresyl violet. Images of the cerebellar cortex layer in lobule VI. The EGL is indicated by a square bracket. Scale bars, $25 \mu \mathrm{m}$. G, Statistical analysis of Purkinje cell dendrites. The length of the dendrites was measured at four sites of primary fissure on four sections prepared from different animals (P8). $\boldsymbol{H}$, Statistical analysis of EGL thickness. The thickness of the EGL was measured at three sites of lobule VI on three sections prepared from different animals (P17). The error bars indicate the SD. ${ }^{* *} p<0.01$ by Student's $t$ test.

examination (Fig. $1 F$ ). However, the differentiation of cerebellar neurons was found to be severely impaired. Abnormal cell morphology was clearly observed in the CAPS2 ${ }^{-/-}$cerebellum at P8. The dendritic arborization of CAPS $2^{-/-}$Purkinje cells (Fig. $2 B$ ) immunostained with an anti-calbindin antibody was reduced to approximately half the average length (Fig. $2 G$ ) of that of wildtype Purkinje cells (Fig. 2 A). Moreover, cerebella impregnated by Golgi staining clearly exhibited a severe reduction in the extent of the spiny dendritic arborization of individual CAPS2 ${ }^{-/-}$Purkinje cells (Fig. 2D) compared with that of wild-type Purkinje cells (Fig. 2C). At P28, the thickness of the ML was almost indistinguishable between wild-type and CAPS2 ${ }^{-1-}$ cerebella, and gross immunostaining patterns with an anti-calbindin antibody appeared to be similar between the wild-type ML and the CAPS $2^{-1-} \mathrm{ML}$; however, the wild-type ML tended to show a slightly higher staining intensity and denser arborization pattern than the CAPS2 $2^{-/-}$ML (Fig. $3 A, D$ ). Golgi staining also showed a less branched dendritic arborization pattern in many CAPS2 $2^{-/-}$ Purkinje cells (Fig. 3G,H). These results suggest that the developmental defect in the Purkinje cells of CAPS $2^{-/-}$mice affects the fine structure of dendritic arborization in adults.

Development of the cerebellar cortex includes dynamic changes in the laminar architecture. The external granular layer (EGL), the site at which robust proliferation of granule cell precursors occurs, thickens progressively until a peak is reached at approximately the first postnatal week; the EGL then gradually thins as the proliferation of these precursors declines, disappearing by the weaning stage, which occurs at approximately the third postnatal week. However, the EGL in the CAPS2 $2^{-1-}$ cerebellum (Fig. $2 F$ ) was still thick (average length, $\sim 22 \mu \mathrm{m}$ ) (Fig. $2 H$ ) at P17, when it was barely detectable in the wildtype cerebellum (Fig. 2E). This difference was observed throughout the whole CAPS2 $2^{-/-}$cerebellum (supplemental Fig. 2, available at www.jneurosci.org as supplemental material). However, by $\mathrm{P} 28$, the EGL was no longer detectable in the CAPS $2^{-/-}$cerebellum (Fig. $1 F$ ).

Next, we analyzed the fine structure of the PF terminals, in which CAPS2 protein primarily associates with the vesicular structures (Sadakata et al., 2004). In the wild-type cerebellum, the vesicular structures within the PF terminals connecting Purkinje cell spines were concentrated near the active zones and were fully distributed over the extrasynaptic area at P15 (Fig. $4 A$ ), whereas in the CAPS $2^{-/-}$cerebellum, the vesicles around the active zones appeared to be located normally, but the vesicles around extrasynaptic sites were considerably reduced in number (Fig. 4B). The terminal buttons of CAPS2 $^{-/-}$PFs also appeared to be larger (Fig. $4 B$, inset) than those of wild-type PFs (Fig. $4 A$, inset). At 12 postnatal weeks, the morphology of PF-PC synapses became indistinguishable between wild-type and CAPS2 $2^{-/-}$cerebella, except in lobules VI and VII. Interestingly, a morphological abnormality of PF-PC synapses in lobules VI and VII of $C A P S 2^{-/-}$cerebellum remained obvious even in the adult. Specifically, there was an increased diameter of presynapses (Fig. $4 \mathrm{H}$ ) and an increased number of divided postsynaptic densities (PSDs) [the ratio of spines containing divided PSDs to the total number spines examined was $0.217(n=60)$ in $C A P S 2^{-/-}$mice vs $0.086(n=58)$ in wild-type mice] (Fig. $4 I)$ [number of PSDs per spine, mean \pm SEM, $1.27 \pm 0.07(n=60)$ in $C A P S 2^{-/-}$mice vs $1.09 \pm 0.04(n=58)$ in wild-type mice; $p<0.01$ by $F$ test] (Fig. $4 J)$.

\section{CAPS2 knock-out impairs neurotrophin secretion}

To determine whether or not the loss of CAPS2 affects neurotrophin secretion, we analyzed the NT-3 immunostaining pattern of cerebellar primary cultures using a confocal microscope. In the wild-type cultures at $8 \mathrm{~d}$ in vitro (DIV), strong NT-3 immunoreactivity was observed in granule cell neurites surrounding Purkinje cells stained for calbindin (Fig. 5A), and the immunoreactivity was also detected in the soma of Purkinje cells, which do not express NT-3; these results indicated the possible internalization of secreted NT-3 after it was bound to Trk receptors (Lindholm et al., 1997). In contrast, NT-3 immunoreactivity merged with calbindin immunoreactivity was markedly reduced in the soma as well as in the dendrites of CAPS2 $2^{-/}$Purkinje cells (Fig. 5B). Similarly, both NT-3 and BDNF immunoreactivity was dimin- 
ished in the Purkinje cells in the CAPS2 ${ }^{-1-}$ cerebellar cortex at P8 (supplemental Fig. 3, available at www. jneurosci.org as supplemental material).

Next, we measured NT-3 secretion in cerebellar cultures. Because of the very low levels of NT-3 expressed in cerebellar cultures, it has remained very difficult to evaluate subtle changes in extracellular NT-3 levels before and after high $\mathrm{KCl}$ stimulation in naive cultures without CAPS2 overexpression (Sadakata et al., 2004). We therefore used a highly sensitive enzyme immunoassay system specific for NT-3 and measured the levels of NT-3 that had been spontaneously secreted and accumulated in the culture medium after an $8 \mathrm{~d}$ culture period (at DIV8) (Katoh-Semba et al., 2000). The results revealed that the loss of CAPS2 led to a reduction in the spontaneous secretion of NT-3 into the culture medium: the NT-3 level in the CAPS $2^{-1-}$ culture medium was only $\sim 36 \%$ of the level in the wild-type culture medium (Fig. 5C), but there was no significant difference between the CAPS2 $2^{-/-}$and wildtype cultures in terms of the total amount of NT-3 in the cell lysates (Fig. 5D). These findings indicated that NT-3 secretion is impaired in the CAPS2 ${ }^{-/-}$cerebellum. Because of the low level of BDNF expression (the BDNF protein content of the cell lysates was only $\sim 10 \%$ of the NT-3 content) in the present study, no secreted BDNF was detected, even in the wild-type culture media, at DIV7, DIV14, or DIV21.

CAPS2 knock-out impairs Trk signaling Secreted neurotrophins bind and activate their Trk receptors on target cells, leading to the autophosphorylation of Trk receptors. We used an anti-pTrk antibody to investigate whether or not the loss of CAPS2 affects the cellular distribution of pTrk in the $\mathrm{CAPS}^{-1-}$ cerebellum (Fig. 6). In the P8 wild-type cerebellum, intense pTrk immunoreactivity was localized around the upper region of the ML, just beneath the EGL, in which the fine tips of the extending dendrites of calbindin-positive Purkinje cells and the PF terminals extending from granule cells are located (Fig. $6 A-C)$. However, this characteristic pTrk immunoreactivity in the upper ML was considerably reduced in the CAPS2 ${ }^{-/-}$cerebellum (Fig. 6D-F). These findings suggested that the loss of CAPS2 resulted in a deficit in neurotrophin-induced Trk activation in target cells.

\section{CAPS2 knock-out causes increased apoptosis of cerebellar neurons}

Because the overexpression of exogenous CAPS2 promotes the survival of cerebellar neurons (Sadakata et al., 2004), we investigated apoptosis in the CAPS $2^{-/-}$cerebellum. The density of apoptotic cells visualized by terminal deoxynucleotidyl transferasemediated biotinylated UTP nick end labeling (TUNEL) assay in the EGL and IGL of each lobule of the cerebellar vermis at P8 was compared in $C A P S 2^{-1-}$ and wild-type littermates (Fig. $7 A, B$ ). In
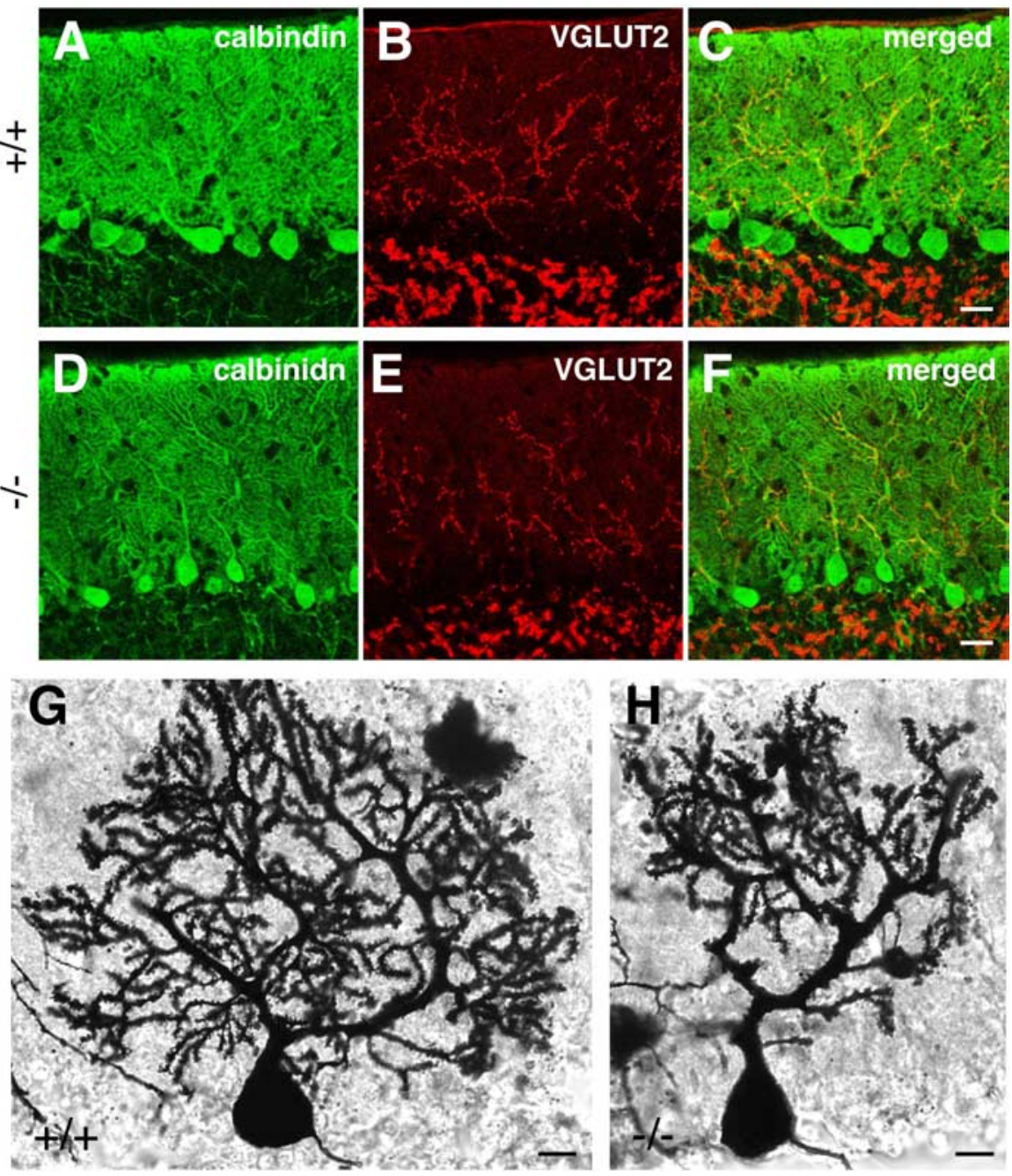

Figure 3. Impaired dendritic arborization of Purkinje cells in the cerebella of P28 CAPS2 $2^{-/-}$mice. $\boldsymbol{A}-\boldsymbol{F}$, Sagittal sections of P28 wild-type (A-C) and CAPS2 ${ }^{-1-}(\boldsymbol{D}-\boldsymbol{F})$ mouse cerebella were immunolabeled with an anti-calbindin antibody (green) and an anti-VGLUT2 (red) antibody. Images of lobule VIII of the cerebellar cortex. Scale bars, $20 \mu \mathrm{m}$. $\mathbf{G}, \boldsymbol{H}$, The dendritic arbors of P28 wild-type (G) and CAPS2 ${ }^{-\prime-}(\boldsymbol{H})$ Purkinje cells were visualized by Golgi staining. Scale bars, $10 \mu \mathrm{m}$.

the CAPS2 $2^{-1-}$ cerebellum, more apoptotic cells were observed in the EGL than in that of the wild-type cerebellum (Fig. 7A), but no such difference was observed in the IGL (Fig. $7 B$ ). Interestingly, the increased cell death in the EGL of the CAPS2 ${ }^{-1-}$ cerebellum was localized in lobules VI-VII and lobule IX. These findings indicated that CAPS2 is required for the survival of granule cells in the EGL, especially in lobules VI-VII and lobule IX, at P8, when CAPS2 expression is upregulated (Sadakata et al., 2004).

\section{CAPS2 knock-out impairs the short-term plasticity of PF-PC synapses}

Because CAPS2 knock-out leads to aberrant cytoarchitecture in PF-PC synapses, as described above (Fig. $4 B$ ), we investigated the synaptic function of PF-PC synapses. However, little difference was found to exist between wild-type and CAPS2 $2^{-/-}$mice in terms of the peak amplitudes of PF-EPSCs (Fig. $8 A$ ), thus indicating that the basic synaptic transmission functions in CAPS $2^{-1-}$ mice are unimpaired.

PPF of the PF-EPSC (defined as the ratio of the amplitude of the second EPSC to that of the first EPSC) is thought to reflect changes in presynaptic function and is considered to be a kind of short-term synaptic plasticity (Atluri and Regehr, 1998). There- 

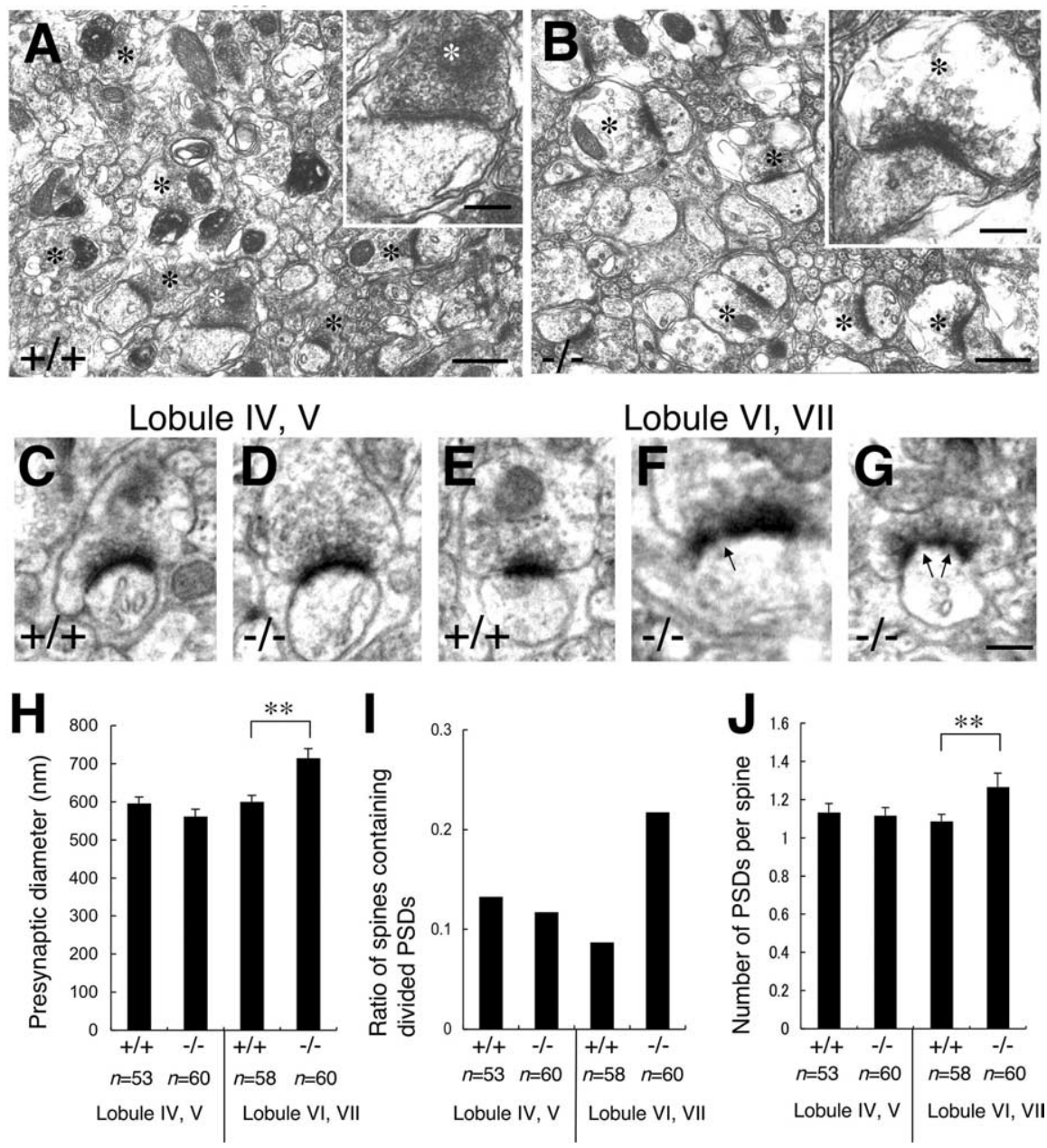

Figure 4. Aberrantly distributed and fewer vesicles within enlarged PF terminals (P15) and an increased number of divided PSDs (P84) in the CAPS2 ${ }^{-/-}$mouse cerebellum. $A, B$, Electron micrographs of a PF-PC synapse in the P15 wild-type cerebellum $(\boldsymbol{A})$ and another in the P15 $C A P S 2^{-/-}$cerebellum $(\boldsymbol{B})$. The insets show higher magnifications. Asterisks represent presynaptic terminals. Scale bars: $500 \mathrm{~nm}$; insets, $200 \mathrm{~nm}$. C $-G$, Electron micrographs of a PF-PC synapse in the P84 wild-type cerebellum (C, $\boldsymbol{E})$ and another in the P84 CAPS2 ${ }^{-1-}$ cerebellum $(\boldsymbol{D}, \boldsymbol{F}, \boldsymbol{G})$. Images of lobules IV-V $(\boldsymbol{C}, \boldsymbol{D})$ and lobules VI-VII $(\boldsymbol{E}-\boldsymbol{G})$ of the cerebellar cortex. Arrows indicate the positions of perforations. Scale bars: $250 \mathrm{~nm}$. $\boldsymbol{H}$, Diameter of presynapses. The error bars indicate the SEM. ${ }^{* *} p<0.01$ by Student's $t$ test. $I$, The ratio of spines containing divided PSDs to the total spines examined. Multiple PSDs in one synapse is defined as a divided PSD.J, Number of PSD s per spine. The error bars indicate the SEM. ${ }^{* *} p<0.01$ by Ftest. Number of synapses examined $(n)$ is indicated.

fore, we performed PPF analysis at PF-PC synapses in the anterior lobe [lobules II-V (Fig. $8 B$ )], central lobe [lobules VI-VII (Fig. $8 C$ )], and posterior lobe [lobule IX (Fig. 8D)]. The results revealed that, for brief interstimulus intervals $(<100 \mathrm{~ms})$, the degree of PPF at PF-PC synapses was markedly lower in $C A P S 2^{-1-}$ mice than in wild-type mice. Impairment of this presynaptic function was observed in all three lobes examined, between P15 and P21 (Fig. $8 B-D$, left). Conversely, in CAPS2 $2^{-/-}$ mice between the ages of P43 and P54, PPF was elicited almost normally in lobules II-V (Fig. $8 \mathrm{~B}$, right) and lobule IX (Fig. $8 D$, right); however, it remained impaired in lobules VI-VII (Fig. $8 C$, right). These results suggested a vulnerability of lobules VI-VII to a loss of CAPS2 function. No significant differences were observed between $C A P S 2^{-/-}$mice and wild-type littermates in terms of cerebellar long-term potentiation (LTP) or long-term depression at the PF-PC synapses (data not shown).

\section{CAPS2 knock-out mice exhibit abnormal behavior}

To assess the cerebellar function of $C A P S 2^{-1-}$ mice, we tested their coordinated motor performance on a rotarod treadmill.

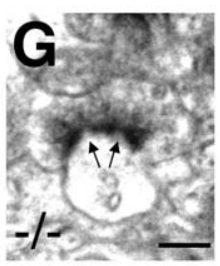

The average number of falls within a $3 \mathrm{~min}$ period at $24 \mathrm{rpm}$ was measured. At P28, CAPS2 $2^{-/-}$mice showed low to moderate rotarod performance compared with that of their wild-type littermates $[2.4 \pm 0.36$ falling times in wild-type mice $(n=16)$ vs $5.6 \pm 1.12$ falling times in CADPS2 ${ }^{-/-}$ mice $(n=14)$, mean \pm SEM; $p<0.01$, by Student's $t$ test]; however, it was of interest that this impairment tended to be relieved at P56 [1.92 \pm 0.70 falling times in wildtype mice $(n=12)$ vs $3.50 \pm 1.34$ falling times in CADPS2 ${ }^{-1-}$ mice $(n=10)$, mean \pm SEM]. Different animals were used between P28 and P56. These findings suggest that CAPS2 ${ }^{-1-}$ mice have an impairment of their motor coordination ability that is with advancing age of the animal capable of recovery by an unknown mechanism that appears to compensate for the loss of CAPS2.

An interesting feature of the CAPS $2^{-/-}$ cerebellum is that characteristic deficits converge on particular lobules: i.e., abnormal lobulation, increased cell death and impaired PPF in adulthood in lobules VIVII, and increased cell death in lobule IX. It is noteworthy that these three lobules have been shown to be associated with the control of various eye movements (Buttner and Fuhry, 1995; Heinen and Keller, 1996). We therefore investigated the vestibulo-ocular reflex and optokinetic response in CAPS2 $2^{-/-}$mice. There were no significant differences between the wildtype and CAPS2 ${ }^{-1-}$ mice in gains of the HVOR (Fig. 9A) or HOKR (Fig. 9C), and the phases of the HVOR were also almost the same in the CAPS2 $2^{-/-}$mice and their wild-type littermates (Fig. 9B). However, the phases of the HOKR were significantly delayed in the CAPS2 $2^{-/-}$mice compared with those of the wild-type mice (Fig. 9D). These findings indicated that the velocity of visually evoked eye movements in CAPS $2^{-/-}$mice tends to lag behind the velocity of the movement of the visual surroundings, whereas no such lag is observed in wild-type mice.

Optokinetic training by sustained exposure to screen oscillations in the presence of a sufficient amount of retinal slip is known to induce cerebellum-dependent adaptation in the HOKR gain (Katoh et al., 1998). Optokinetic training for $1 \mathrm{~h}$ by sustained exposure to $15^{\circ}, 0.17 \mathrm{~Hz}$ screen oscillations did induce a substantial increase in the HOKR gain in the wild-type mice, but the same training induced no significant change in the HOKR gain in the CAPS2 $2^{-/-}$mice (Fig. 9E). Together, these observations demonstrate that the loss of CAPS2 led to an eye movement disorder characterized by impaired HOKR gain and plasticity.

\section{Discussion}

By targeted gene disruption, we obtained in vivo evidence of the importance of CAPS2 in cerebellar development and function. CAPS2 is a secretory granule-associated protein that is highly expressed in the cerebellum (Speidel et al., 2003; Sadakata et al., 

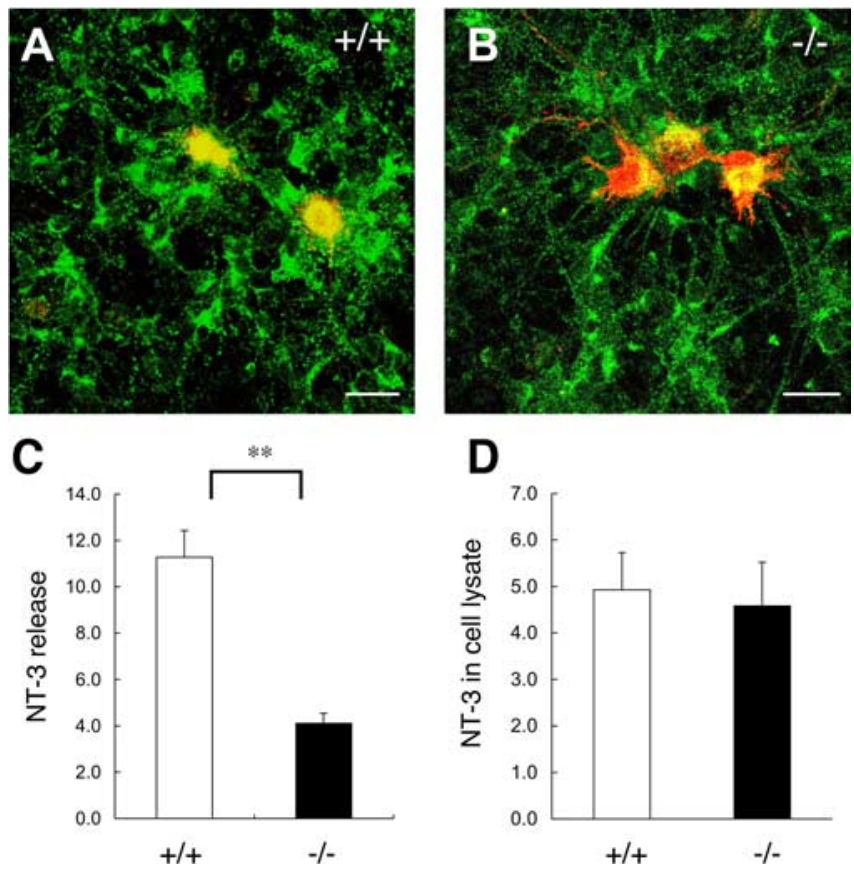

Figure 5. Decreased immunoreactivity of internalized NT-3 in the Purkinje cells of a CAPS2 $^{-1-}$ primary culture (confocal image) and decreased NT-3 release activity in the culture. $\boldsymbol{A}, \boldsymbol{B}$, Cerebellar primary cultures (DIV8) from wild-type mice $(\boldsymbol{A})$ and $C A P S 2^{-1-}$ mice $(\boldsymbol{B})$ were immunolabeled with an anti-NT-3 antibody (green) and an anti-calbindin (red) antibody. Scale bars, $20 \mu \mathrm{m}$. C, NT-3 release activity in the wild-type (open bars) and CAPS2 ${ }^{-/-}$(filled bars) cerebellum was evaluated by measuring the levels of NT-3 spontaneously secreted into the culture medium by cerebellar primary dissociation cultures at DIV8 with an enzyme immunoassay. The $y$-axis shows NT-3 density corrected for whole-cell density (arbitrary unit). D, The amount of NT-3 in the cell lysates of wild-type (open bars) and CAPS2 ${ }^{-/-}$(filled bars) cultures was evaluated as indicated in C. The $y$-axis shows NT-3 density corrected for whole-cell density (arbitrary unit). The error bars indicate the SD. ${ }^{* *} p<0.01$ by Student's $t$ test.

2004). CAPS $2^{-/-}$mice exhibit many deficits in cerebellar development, including loss of the intercrural fissure between lobules VI and VII and impaired dendritic arborization of Purkinje cells, both of which were observed in adult mice, and delayed granule cell migration during development. Several deficits at the cellular level and at the level of synapse function were also identified in CAPS2 ${ }^{-1-}$ mice, including impaired neurotrophin secretion and Trk signaling, increased neuronal apoptosis, and impaired shortterm plasticity (PPF) at PF-PC synapses. Moreover, CAPS2 $2^{-1-}$ mice exhibit impaired motor coordination and eye movement (HOKR), suggesting that their developmental deficits cause abnormal cerebellar functioning.

\section{Involvement of CAPS2 in neurotrophin release}

Our previous study found that overexpression of exogenous CAPS2 enhances the depolarization-induced release of exogenously expressed BDNF from PC12 cells (Sadakata et al., 2004). The present study confirmed this finding by showing that a loss of CAPS2 leads to a reduction in the spontaneous release of endogenous NT-3 into the media of cerebellar primary cultures. The spontaneous NT-3 release appears to occur either via a regulated pathway induced by spontaneous neural activities or via a constitutive pathway. However, our recent study showed that loss of CAPS2 function affects both constitutive and regulated release of exogenously expressed BDNF from cerebellar cultures (Sadakata et al., 2007b). Therefore, we suggest that CAPS2 plays a role in a common mechanism shared by the regulatory and constitutive secretion processes.
The secretion defect in CAPS2 $2^{-/-}$mice might be expected to induce an accumulation of neurotrophin in granule cells, but there was no significant difference in the total amount of NT-3 between the cell lysates of primary cultured cells from CAPS2 $2^{-1-}$ and wild-type mice. It has been reported that BDNF increases the level of NT-3 expression in granule cells (Leingartner et al., 1994; Ichikawa et al., 1998). Thus, the absence of such neurotrophic actions resulting from a loss of CAPS2 may exert an influence on the NT-3 level in the cell lysates of CAPS2 $2^{-/-}$primary cultured cells.

In addition to BDNF in cerebellar granule cells, BDNF in the inferior olive (Conner et al., 1997; Li et al., 2001) is thought to act on postsynaptic Purkinje cells via presynaptic CF terminals originating from the inferior olive (Sherrard and Bower, 2002). CAPS1, but not CAPS2, is expressed in the inferior olive (Sadakata et al., 2006) and was colocalized with VGLUT2 (supplemental Fig. 1, available at www.jneurosci.org as supplemental material), a CF terminal marker, around the proximal dendrites of Purkinje cells, suggesting the possible involvement of CAPS1 in BDNF release from CF terminals. In the CAPS2 $2^{-1-}$ cerebellum, VGLUT2-immunostained CF terminals ascend normally to the proximal dendrites of Purkinje cells as in the wild-type. These results indicate that there is no significant compensatory or negative effect attributable to CAPS1-mediated secretion from climbing fibers, on the physiological and behavioral phenotypes observed in CAPS2 $2^{-/-}$mice.

\section{Comparison of CAPS2 $2^{-/-}$cerebellum with $\mathrm{BDNF}^{-/-}$and $N T-3^{-1-}$ cerebellum}

CAPS2 $2^{-1-}$ mice have phenotypes similar to those observed in $B D N F^{-1-}$ mice (Jones et al., 1994; Schwartz et al., 1997; Carter et al., 2002) and cerebellum-specific NT-3 knock-out mice (Bates et al., 1999), e.g., aberrant arborization of Purkinje cells $\left[B D N F^{-/-}\right.$ mice (Schwartz et al., 1997; Carter et al., 2002)], a thicker EGL at P17 [BDNF ${ }^{-/-}$mice (Jones et al., 1994; Schwartz et al., 1997)], increased apoptosis and a lobulation deficit $\left[B D N F^{-/-}\right.$mice (Schwartz et al., 1997) and NT-3 ${ }^{-/-}$mice (Bates et al., 1999)], presynaptic swelling of PF terminals $\left[B D N F^{-/-}\right.$mice (Carter et al., 2002)], and impaired PPF at PF-PC synapses $\left[B D N F^{-/-}\right.$mice (Carter et al., 2002)]. The enlarged PF terminal buttons of CAPS2 ${ }^{-/-}$mice are also reminiscent of the enlarged presynaptic buttons in the hippocampal neurons of $\operatorname{TrkB}^{-/-}$animals (Martinez et al., 1998). Thus, in addition to deficits in the neurotrophin-Trk signaling (i.e., decreases in BDNF and NT-3 release and in the consequent phosphorylation of Trk receptors), these morphological and physiological phenotypes of CAPS2 $2^{-1-}$ mice also imply that CAPS2 function is closely correlated with the neurotrophic actions of BDNF and NT-3 in the cerebellum.

However, CAPS2 ${ }^{-/-}$mice exhibited several other phenotypes distinct from those of $B D N F$ and NT-3 mutant mice: $B D N F^{-/-}$ mice have a short lifespan (Jones et al., 1994) and NT-3 ${ }^{-/-}$mice die soon after birth (Ernfors et al., 1994), whereas CAPS2 $2^{-\prime-}$ mice are viable and display impairment of both motor coordination and eye movements. Thus, the present results raise an intriguing question: is CAPS2 associated with the pivotal roles of BDNF and/or NT-3 in other brain regions besides the cerebellum? CAPS2 protein codistributed with BDNF and NT-3 in various brain regions, including the cerebral cortex, hippocampus, and mesencephalic tegmentum, although the distribution patterns of these proteins do not completely overlap throughout the brain, e.g., BDNF in the hypothalamus is codistributed with CAPS1 rather than with CAPS2 (Sadakata et al., 2006b). Thus, it cannot be ruled out that, in some brain regions, CAPS1 is in- 

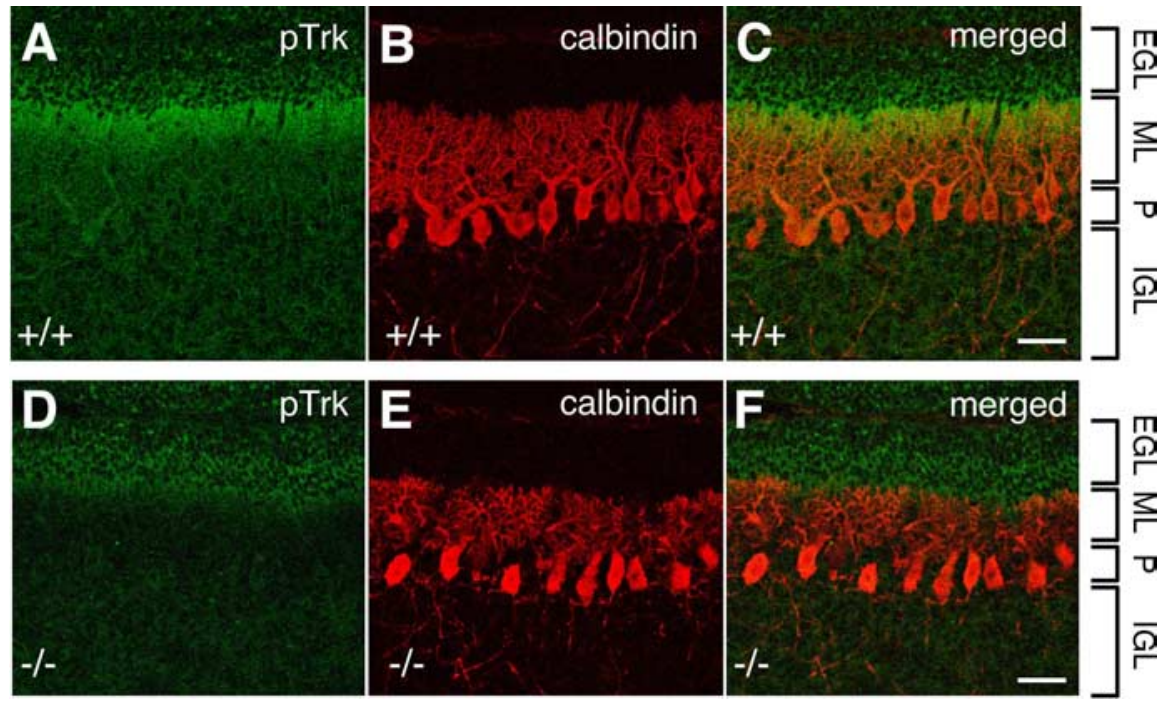

Figure 6. Decreased immunoreactivity of phosphorylated Trk (Tyr490) in the Purkinje cell dendrites of CAPS2 ${ }^{-1-}$ mice. $\boldsymbol{A}-\boldsymbol{F}$, Sagittal sections of P8 wild-type $(\boldsymbol{A}-\boldsymbol{C})$ and $C A P S 2^{-1-}(\boldsymbol{D}-\boldsymbol{F})$ cerebella were immunolabeled with an anti-phosphorylated Trk antibody (green) and an anti-calbindin (red) antibody. Images of lobule IX of the cerebellar cortex are shown. Similar staining patterns were observed throughout the cerebellar cortices of wild-type and CAPS2 ${ }^{-1-}$ mice. P, Purkinje cell layer. Scale bars, $25 \mu \mathrm{m}$.
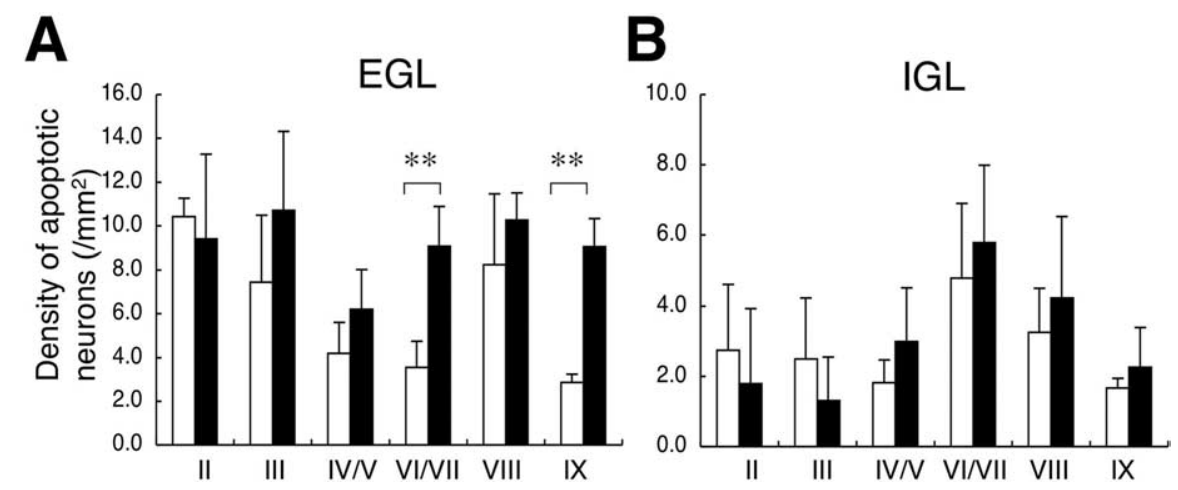

Figure 7. Apoptotic cell density in the CAPS2 $2^{-/-}$mouse cerebellum. $\boldsymbol{A}, \boldsymbol{B}$, Apoptotic cell density in the EGL $(\boldsymbol{A})$ and IGL $(\boldsymbol{B})$ of each lobule of the wild-type (open bars) and CAPS2 ${ }^{-/-}$(filled bars) cerebellum (TUNEL assay). The error bars indicate the SD. ${ }^{* *} p<0.01$ by Student's $t$ test.

volved in the secretion of BDNF and/or NT-3 and that CAPS2 mediates the secretion of secretory substances other than BDNF and NT-3. Additional study of CAPS2 itself and of CAPS2 $2^{-1-}$ mouse will help to clarify the role(s) played by CAPS2-mediated neurotrophin secretion in various brain regions.

Because both $B D N F^{-1-}$ mice (Jones et al., 1994) and NT-3 ${ }^{-1-}$ mice (Ernfors et al., 1994) die during the early postnatal period, the effects of BDNF or NT-3 deficiency on the fine structure of the cerebellum cannot be analyzed in adulthood. Interestingly, the adult CAPS2 ${ }^{-1-}$ cerebellum showed abnormal divided PSDs at PF-PC synapses. It has been proposed that LTP in hippocampal neurons induces an increase in PSD size, resulting in the formation of "perforated PSDs," followed by spine splitting (Luscher et al., 2000); however, this remains controversial (Harris et al., 2003). We did not observe clear images showing evidence of spine splitting in CAPS2 ${ }^{-/-} \mathrm{PF}-\mathrm{PC}$ synapses. We suggest that the aberrant morphology of PSDs at CAPS2 $2^{-/-} \mathrm{PF}-\mathrm{PC}$ synapses is a sign of degenerative PSD fragmentation rather than being related to a property of normal synapses.

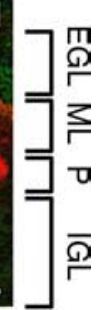

\section{Localized phenotypes of}

CAPS2 $2^{-1-}$ cerebellum

It is of interest that some of the deficits in CAPS2 $2^{-/-}$mice are localized in particular cerebellar compartments. Impaired dendritic arborization of Purkinje cells, a delay in granule cell proliferation and migration, decreased Trk phosphorylation, and impaired PPF at an early stage are all observed throughout the developing cerebellar cortex. On the contrary, increased apoptosis in lobules VI-VII and lobule IX, a lobulation deficit between lobules VI and VII, an increase in the number of divided PSDs and the diameter of presynapses in lobules VI-VII in adulthood, and impaired PPF in lobules VI-VII in adulthood all represent lobule-specific phenotypes in the $C A P S 2^{-1-}$ cerebellum. BDNF and NT-3 knock-out mice also show a lobulation deficit between lobules VI and VII (Schwartz et al., 1997; Bates et al., 1999). Katoh-Semba et al. (2000) showed a higher concentration of NT-3 in posterior lobules than in anterior lobules and that depletion of NT-3 from the mouse brain causes an increase in granule cell apoptosis within lobules VI-VII, suggesting that the requirement of neurotrophins for granule cell survival seems to be different between cerebellar lobules. In this regard, it is noteworthy that there are localized high BDNF protein levels in lobules VI, VII, and IX and localized high NT-3 mRNA levels in lobules VI and IX during development (supplemental Fig. 4, available at www. jneurosci.org as supplemental material). Together, these results suggest that lobules VI-VII and IX express more BDNF and NT-3 than do the other cerebellar compartments during development; thus, these lobules are more susceptible to the effects of depletion of these neurotrophins. Moreover, the developmental and spatial deficits in CAPS $2^{-1-}$ cerebellum seem to be related to the regional time course of cerebellar development (the granule cell proliferation and differentiation is either delayed or more prolonged in lobules VI-VII than the other vermal lobules) as well as the differential peak stages of BDNF and NT-3 expression (Katoh-Semba et al., 1997, 2000). Conversely, secretion from CF terminals is probably not associated with the localized phenotypes of the CAPS2 $2^{-/-}$cerebellum, because no significant change could be seen in the overall ascending patterns of VGLUT2immunopositive climbing fibers between wild-type and CAPS2 $2^{-/-}$mice. However, the possibility that a trophic effect (e.g., sonic hedgehog) from Purkinje cells might secondarily affect granule cell survival should not be ruled out (Sotelo, 2004), because the development of Purkinje cells is impaired in CAPS2 ${ }^{-/-}$mice.

It is difficult to conclude whether the localized increase in BDNF immunoreactivity is present in "recipient" or "donor" cells, because BDNF released from cerebellar granule cells acts in an autocrine manner in the IGL, as shown by the immunoreac- 
tivity of phosphorylated Trk (Schwartz et al., 1997). The localized increase in BDNF immunoreactivity in lobules VI-VII and IX was observed in both the wild-type and CAPS2 $^{-1-}$ cerebellum (data not shown). Therefore, it is suggested that localized increase in the immunoreactivity for BDNF in the IGL is probably attributable to an increase in BDNF levels in donor granule cells.

At the physiological and behavioral levels, it is of interest that decreased PPF was observed only in lobules VI-VII during adulthood. Lobules VI, VII, and IX are known to be associated with the control of various eye movements (Buttner and Fuhry, 1995; Heinen and Keller, 1996). In primates, lesions in lobules VI-VII cause saccadic dysmetria and smooth pursuit deficits (Buttner and Fuhry, 1995), and lesions in lobule IX of the vermis (uvula) lead to optokinetic and smooth pursuit deficits (Heinen and Keller, 1996). Therefore, the impaired control of eye movements in CAPS2 $2^{-1-}$ mice is most likely attributable to deficits in these cerebellar compartments.

\section{CAPS2 gene disruption and}

autistic phenotypes

A recent study by our group showed that CAPS2 knock-out mice have autistic-like cellular and behavioral phenotypes. Moreover, we found in blood samples from some autistic patients an aberrant alternative splicing variant of CAPS $2 \mathrm{mRNA}$ that lacks a specific exon encoding the dynactin 1-binding domain, which is required for proper axonal transport (Sadakata et al., 2007b). Autism is characterized by cerebellar morphological abnormalities (Bauman and Kemper, 1985; Courchesne et al., 1988). In this report, we focused on the cerebellar phenotypes of CAPS2 knock-out mice and found that CAPS2 $2^{-1-}$ mice show the cerebellar phenotypes described above. Some of these phenotypes are similar with those observed in autistic patients. Abnormal reduction in lobules VI and VII of the cerebellar vermis is a characteristic morphological deficit reported in the brains of autistic patients (Courchesne et al., 1988), and hypoplasia of these lobules was suggested to be related to the abnormal exploratory behavior of autism (Pierce and Courchesne, 2001). Deficits in pursuit eye movement (Takarae et al., 2004) and motor coordination (Manjiviona and Prior, 1995) have also been reported in autistic spectrum disorders. Moreover, decreased PPF (Moretti et al., 2006) was shown in a mouse model of Rett syndrome (Chen et al., 2001; Guy et al., 2001), which is considered to be an autistic spectrum disorder (World Health

B

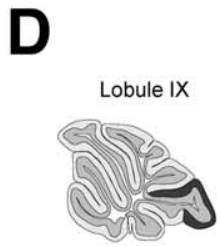

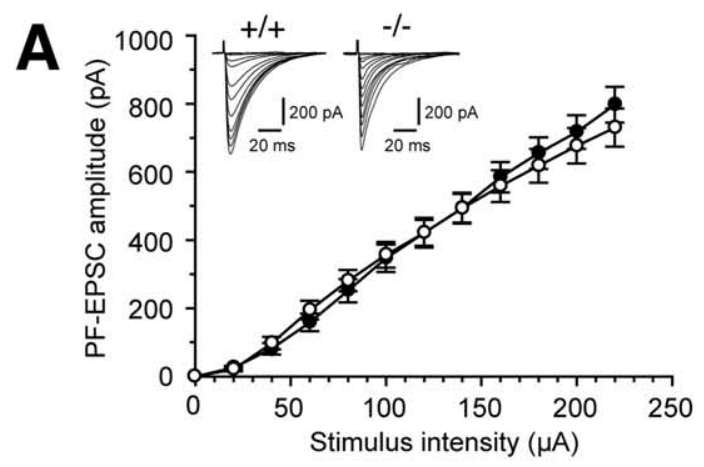
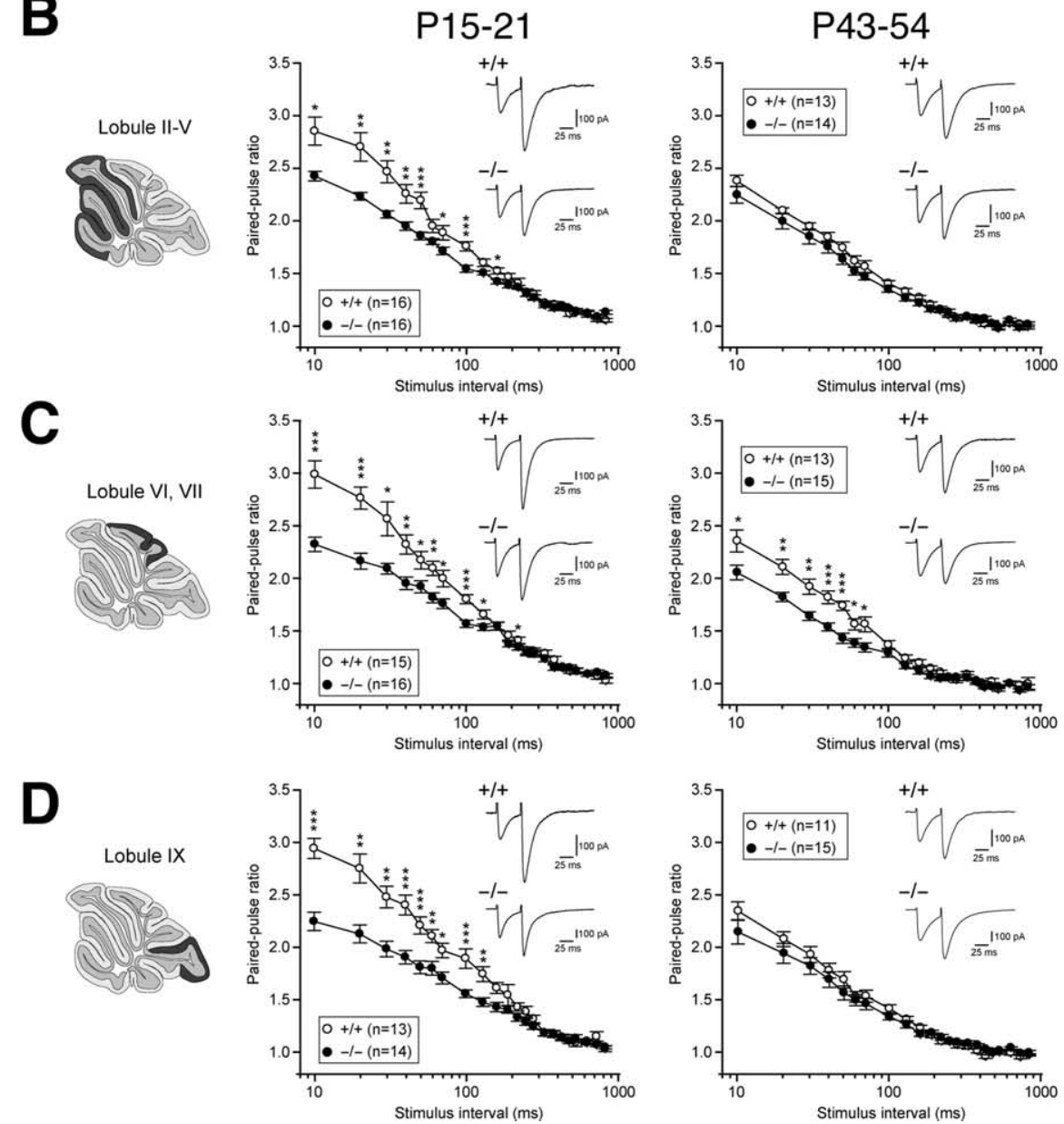

Figure 8. Impairment of short-term synaptic plasticity at PF-PC synapses in the CAPS2 ${ }^{-1-}$ mouse cerebellum. $\boldsymbol{A}$, Plots showing the relationship between the PF-EPSC amplitude and stimulus intensity applied to PFs in CAPS2 $2^{-1-}$ mice (filled circles; $n=16$ ) and wild-type littermates (open circles; $n=18$ ), at P15-P21. Insets show representative EPSC traces evoked by PF stimuli of different intensities (0-220 $\mu \mathrm{A}, 20 \mu \mathrm{A}$ intervals). $\boldsymbol{B}-\boldsymbol{D}$, The mean paired-pulse ratios recorded from each lobule of P15-P21 (left column) and P43-P54 (right column) cerebellar slices were plotted against various interstimulus intervals. Recordings from lobules II-V, VI-VII, and IX are shown in $\boldsymbol{B}, \boldsymbol{C}$, and $\boldsymbol{D}$, respectively. Insets show representative traces obtained from CAPS2 ${ }^{-/-}$mice and wild-type littermates. CAPS2 $2^{-1-}$ mice exhibited a lower PPF ratio than their wild-type littermates at interstimulus intervals of $<100$ ms in all lobules at P15-P21 and in lobules VI-VII only at P43-P54. The error bars indicate the SEM. ${ }^{*} p<0.05$; ${ }^{* *} p<$ $0.01{ }^{* * *} p<0.001$ by the Mann-Whitney $U$ test.
Organization, 1992; American Psychiatric Association, 1994). Together, our findings are also suggestive of an involvement of the CAPS2 gene, which is located within the AUTS1, in the cerebellar deficits of autistic patients.

In conclusion, the present CAPS2 ${ }^{-/-}$mouse study indicated that CAPS2-mediated neurotrophin release is indispensable for cerebellum-related cellular, morphological, physiological, and 
A
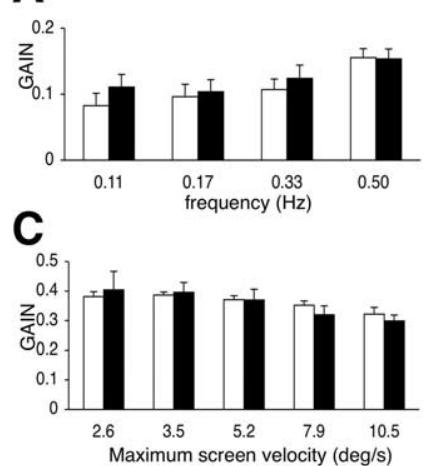

B
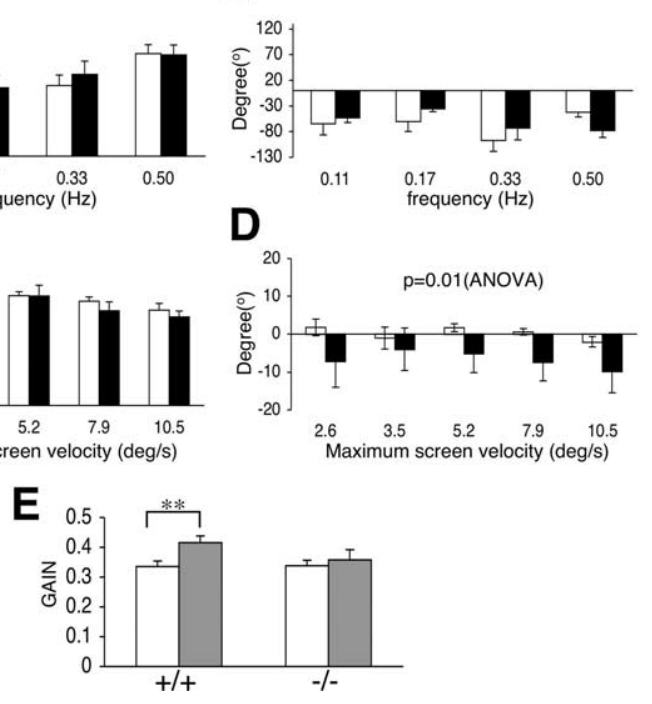

Figure 9. Impairments in the eye movement plasticity of $C A P S 2^{-/-}$mice. $A, B, H V O R$. Gain $(\boldsymbol{A})$ and phase $(\boldsymbol{B})$ of 6-month-old $C A P S 2^{-1-}$ mice (filled bars; $\left.n=8\right)$ and wild-type littermates (open bars; $n=8)$ ). C, D, HOKR. Gain $(\boldsymbol{C})$ and phase $(\boldsymbol{D})$ of 6 -month-old CAPS2 ${ }^{-1-}$ mice (filled bars; $n=9$ ) and wild-type littermates (open bars; $n=9$ ). The HOKR phase lags of the CAPS2 $2^{-/-}$mice were longer than those of the wild-type mice at all screen velocities ( $p=0.01$, two-way ANOVA). $\boldsymbol{E}$, Optokinetic training was performed by exposing the mice to $1 \mathrm{~h}$ of sustained sinusoidal screen oscillations by $15^{\circ}$ (peak-to-peak) at $0.17 \mathrm{~Hz}$. The mean HOKR gains before (open bars) and after (gray bars) training of the CAPS2 ${ }^{-/-}(n=9)$ and wild-type ( $n=$ 8) mice are shown. The error bars indicate the SEM. ${ }^{* *} p<0.01$ by Student's $t$ test.

behavioral phenotypes, some of which appear to be related to the cerebellar deficits observed in autistic patients. Thus, it appears that this disturbance in CAPS2-mediated neurotrophic release could be at least in part responsible for the onset of autistic disorder.

\section{References}

American Psychiatric Association (1994) Diagnostic and statistical manual of mental disorders: DSM-IV. Washington, DC: American Psychiatric Association.

Atluri PP, Regehr WG (1998) Delayed release of neurotransmitter from cerebellar granule cells. J Neurosci 18:8214-8227.

Bates B, Rios M, Trumpp A, Chen C, Fan G, Bishop JM, Jaenisch R (1999) Neurotrophin-3 is required for proper cerebellar development. Nat Neurosci 2:115-117.

Bauman M, Kemper TL (1985) Histoanatomic observations of the brain in early infantile autism. Neurology 35:866-874.

Berwin B, Floor E, Martin TF (1998) CAPS (mammalian UNC-31) protein localizes to membranes involved in dense-core vesicle exocytosis. Neuron 21:137-145.

Bibel M, Barde YA (2000) Neurotrophins: key regulators of cell fate and cell shape in the vertebrate nervous system. Genes Dev 14:2919-2937.

Binda AV, Kabbani N, Levenson R (2005) Regulation of dense core vesicle release from $\mathrm{PC} 12$ cells by interaction between the $\mathrm{D} 2$ dopamine receptor and calcium-dependent activator protein for secretion (CAPS). Biochem Pharmacol 69:1451-1461.

Buttner U, Fuhry L (1995) Eye movements. Curr Opin Neurol 8:77-82.

Carter AR, Chen C, Schwartz PM, Segal RA (2002) Brain-derived neurotrophic factor modulates cerebellar plasticity and synaptic ultrastructure. J Neurosci 22:1316-1327.

Chen RZ, Akbarian S, Tudor M, Jaenisch R (2001) Deficiency of methylCpG binding protein-2 in CNS neurons results in a Rett-like phenotype in mice. Nat Genet 27:327-331.

Cisternas FA, Vincent JB, Scherer SW, Ray PN (2003) Cloning and characterization of human CADPS and CADPS2, new members of the $\mathrm{Ca}^{2+}$ dependent activator for secretion protein family. Genomics 81:279-291.

Conner JM, Lauterborn JC, Yan Q, Gall CM, Varon S (1997) Distribution of brain-derived neurotrophic factor (BDNF) protein and mRNA in the normal adult rat CNS: evidence for anterograde axonal transport. J Neurosci 17:2295-2313.

Courchesne E, Yeung-Courchesne R, Press GA, Hesselink JR, Jernigan TL (1988) Hypoplasia of cerebellar vermal lobules VI and VII in autism. N Engl J Med 318:1349-1354.

Ernfors P, Lee KF, Kucera J, Jaenisch R (1994) Lack of neurotrophin-3 leads to deficiencies in the peripheral nervous system and loss of limb proprioceptive afferents. Cell 77:503-512.

Grishanin RN, Kowalchyk JA, Klenchin VA, Ann K, Earles CA, Chapman ER, Gerona RR, Martin TF (2004) CAPS acts at a prefusion step in densecore vesicle exocytosis as a PIP 2 binding protein. Neuron 43:551-562.

Guy J, Hendrich B, Holmes M, Martin JE, Bird A (2001) A mouse Mecp2null mutation causes neurological symptoms that mimic Rett syndrome. Nat Genet 27:322-326.

Harris KM, Fiala JC, Ostroff L (2003) Structural changes at dendritic spine synapses during long-term potentiation. Philos Trans R Soc Lond B Biol Sci 358:745-748.

Heinen SJ, Keller EL (1996) The function of the cerebellar uvula in monkey during optokinetic and pursuit eye movements: single-unit responses and lesion effects. Exp Brain Res 110:1-14.

Huang EJ, Reichardt LF (2001) Neurotrophins: roles in neuronal development and function. Annu Rev Neurosci 24:677-736.

Ichikawa D, Tabuchi A, Taoka A, Tsuchiya T, Tsuda M (1998) Attenuation of cell death mediated by membrane depolarization different from that by exogenous BDNF in cultured mouse cerebellar granule cells. Brain Res Mol Brain Res 56:218-226.

International Molecular Genetic Study of Autism Consortium (2001) Further characterization of the autism susceptibility locus AUTS1 on chromosome 7q. Hum Mol Genet 10:973-982.

Jastreboff PW (1979) Evaluation and statistical judgement of neural responses to sinusoidal stimulation in cases with superimposed drift and noise. Biol Cybern 33:113-120.

Jones KR, Farinas I, Backus C, Reichardt LF (1994) Targeted disruption of the BDNF gene perturbs brain and sensory neuron development but not motor neuron development. Cell 76:989-999.

Katoh A, Kitazawa H, Itohara S, Nagao S (1998) Dynamic characteristics and adaptability of mouse vestibulo-ocular and optokinetic response eye movements and the role of the flocculo-olivary system revealed by chemical lesions. Proc Natl Acad Sci USA 95:7705-7710.

Katoh-Semba R, Kaisho Y, Shintani A, Nagahama M, Kato K (1996) Tissue distribution and immunocytochemical localization of neurotrophin-3 in the brain and peripheral tissues of rats. J Neurochem 66:330-337.

Katoh-Semba R, Takeuchi IK, Semba R, Kato K (1997) Distribution of brain-derived neurotrophic factor in rats and its changes with development in the brain. J Neurochem 69:34-42.

Katoh-Semba R, Takeuchi IK, Semba R, Kato K (2000) Neurotrophin-3 controls proliferation of granular precursors as well as survival of mature granule neurons in the developing rat cerebellum. J Neurochem 74:1923-1930.

Kawase E, Suemori H, Takahashi N, Okazaki K, Hashimoto K, Nakatsuji N (1994) Strain difference in establishment of mouse embryonic stem (ES) cell lines. Int J Dev Biol 38:385-390.

Kovalchuk Y, Holthoff K, Konnerth A (2004) Neurotrophin action on a rapid timescale. Curr Opin Neurobiol 14:558-563.

Leingartner A, Heisenberg CP, Kolbeck R, Thoenen H, Lindholm D (1994) Brain-derived neurotrophic factor increases neurotrophin-3 expression in cerebellar granule neurons. J Biol Chem 269:828-830.

Lessmann V, Gottmann K, Malcangio M (2003) Neurotrophin secretion: current facts and future prospects. Prog Neurobiol 69:341-374.

Li YX, Tokuyama W, Okuno H, Miyashita Y, Hashimoto T (2001) Differential induction of brain-derived neurotrophic factor mRNA in rat inferior olive subregions following unilateral labyrinthectomy. Neuroscience 106:385-394.

Lindholm D, Hamner S, Zirrgiebel U (1997) Neurotrophins and cerebellar development. Perspect Dev Neurobiol 5:83-94.

Lu B (2003) BDNF and activity-dependent synaptic modulation. Learn Mem 10:86-98.

Luscher C, Nicoll RA, Malenka RC, Muller D (2000) Synaptic plasticity and dynamic modulation of the postsynaptic membrane. Nat Neurosci 3:545-550.

Lynch A, Smart JL, Dobbing J (1975) Motor co-ordination and cerebellar size in adult rats undernourished in early life. Brain Res 83:249-259. 
Manjiviona J, Prior M (1995) Comparison of Asperger syndrome and highfunctioning autistic children on a test of motor impairment. J Autism Dev Disord 25:23-39.

Martinez A, Alcantara S, Borrell V, Del Rio JA, Blasi J, Otal R, Campos N, Boronat A, Barbacid M, Silos-Santiago I, Soriano E (1998) TrkB and TrkC signaling are required for maturation and synaptogenesis of hippocampal connections. J Neurosci 18:7336-7350.

Moretti P, Levenson JM, Battaglia F, Atkinson R, Teague R, Antalffy B, Armstrong D, Arancio O, Sweatt JD, Zoghbi HY (2006) Learning and memory and synaptic plasticity are impaired in a mouse model of Rett syndrome. J Neurosci 26:319-327.

Muhle R, Trentacoste SV, Rapin I (2004) The genetics of autism. Pediatrics 113:e472-e486.

Pierce K, Courchesne E (2001) Evidence for a cerebellar role in reduced exploration and stereotyped behavior in autism. Biol Psychiatry 49:655-664.

Renden R, Berwin B, Davis W, Ann K, Chin CT, Kreber R, Ganetzky B, Martin TF, Broadie K (2001) Drosophila CAPS is an essential gene that regulates dense-core vesicle release and synaptic vesicle fusion. Neuron 31:421-437.

Sadakata T, Mizoguchi A, Sato Y, Katoh-Semba R, Fukuda M, Mikoshiba K, Furuichi T (2004) The secretory granule-associated protein CAPS2 regulates neurotrophin release and cell survival. J Neurosci 24:43-52.

Sadakata T, Itakura M, Kozaki S, Sekine Y, Takahashi M, Furuichi T (2006) Differential distributions of the $\mathrm{Ca}^{2+}$-dependent activator protein for secretion family proteins (CAPS2 and CAPS1) in the mouse brain. J Comp Neurol 495:735-753.

Sadakata T, Washida M, Morita N, Furuichi T (2007a) Tissue distribution of $\mathrm{Ca}^{2+}$-dependent activator protein for secretion family members CAPS1 and CAPS2 in mice. J Histochem Cytochem, in press.

Sadakata T, Washida M, Iwayama Y, Shoji S, Sato Y, Ohkura T, Katoh-Semba R, Nakajima M, Sekine Y, Tanaka M, Nakamura K, Iwata Y, Tsuchiya KJ, Mori N, Detera-Wadleigh SD, Ichikawa H, Itohara S, Yoshikawa T, Fu- ruichi T (2007b) Autistic-like phenotypes in CADPS2/CAPS2 knockout mice and aberrant CADPS2 splicing in autistic patients. J Clin Invest, in press.

Schinder AF, Poo M (2000) The neurotrophin hypothesis for synaptic plasticity. Trends Neurosci 23:639-645.

Schwartz PM, Borghesani PR, Levy RL, Pomeroy SL, Segal RA (1997) Abnormal cerebellar development and foliation in $\mathrm{BDNF}^{-1-}$ mice reveals a role for neurotrophins in CNS patterning. Neuron 19:269-281.

Segal RA (2003) Selectivity in neurotrophin signaling: theme and variations. Annu Rev Neurosci 26:299-330.

Sherrard RM, Bower AJ (2002) Climbing fiber development: do neurotrophins have a part to play? Cerebellum 1:265-275.

Sotelo C (2004) Cellular and genetic regulation of the development of the cerebellar system. Prog Neurobiol 72:295-339.

Speidel D, Varoqueaux F, Enk C, Nojiri M, Grishanin RN, Martin TF, Hofmann K, Brose N, Reim K (2003) A family of $\mathrm{Ca}^{2+}$-dependent activator proteins for secretion: comparative analysis of structure, expression, localization, and function. J Biol Chem 278:52802-52809.

Speidel D, Bruederle CE, Enk C, Voets T, Varoqueaux F, Reim K, Becherer U, Fornai F, Ruggieri S, Holighaus Y, Weihe E, Bruns D, Brose N, Rettig J (2005) CAPS1 regulates catecholamine loading of large dense-core vesicles. Neuron 46:75-88.

Takarae Y, Minshew NJ, Luna B, Krisky CM, Sweeney JA (2004) Pursuit eye movement deficits in autism. Brain 127:2584-2594.

Tandon A, Bannykh S, Kowalchyk JA, Banerjee A, Martin TF, Balch WE (1998) Differential regulation of exocytosis by calcium and CAPS in semi-intact synaptosomes. Neuron 21:147-154.

Thoenen H (1995) Neurotrophins and neuronal plasticity. Science 270:593-598.

World Health Organization (1992) The ICD-10 classification of mental and behavioural disorders: clinical descriptions and diagnostic guidelines. Geneva: World Health Organization. 